\title{
Detection of anti-colon antibodies in inflammatory bowel disease using human cultured colonic cells
}

\author{
J C W Lee, A M Cevallos, A Naeem, J E Lennard-Jones, M J G Farthing
}

\begin{abstract}
Background-Investigation of anti-colon antibodies may be simplified if a sensitive method and homogeneous source of antigen were available.

Aims-To examine the anti-colon antibody response using human colonic carcinoma cell lines as antigen.

Subjects-Patients with inflammatory bowel disease and other gastrointestinal disorders and healthy controls were studied.

Methods-Comparative enzyme linked immunosorbent assays (ELISAs) were performed to assess the value of whole Caco-2, HT-29, and LS-180 cells as antigen. The antigenic determinants of the immune response were characterised by western blot analysis.

Results-Sera demonstrated immunoreactivity against each of the cell lines, but different epitopes were recognised. Applying whole Caco-2 cells as antigen in an ELISA, the prevalence of anti-colon antibodies was significantly greater in patients with ulcerative colitis (36\%) than Crohn's disease $(13 \%)$, other gastrointestinal disorders (13\%) and healthy controls (0) $(p<0.05)$. The immune response was not associated with one predominant antigen. Conclusions-Fixed whole cell ELISA is a simple and feasible method for studying the anti-colon antibody response. This response is non-specific, being directed against multiple antigens, and is likely to be an epiphenomenon of inflammatory bowel disease, more so for ulcerative colitis than Crohn's disease.

(Gut 1999;44:196-202)
\end{abstract}

Keywords: anti-colon antibodies; inflammatory bowel disease

The aetiology of ulcerative colitis and Crohn's disease is unknown. The possibility that autoimmune antibody responses contribute to their pathogenesis has been suggested by the presence of antibodies directed against colonic epithelial cells. However, a precise role for these antibodies is yet to be defined and the specific antigenic determinants of the response remains to be characterised.

The reported prevalence of anti-colon antibodies in patients with inflammatory bowel disease (IBD) varies from less than $20 \%$ in some studies to over $70 \%$ in others. ${ }^{1-3}$ This variation may be due, in part, to the absence of a standard immunological assay for their detection. The diverse investigative methods used include qualitative assessment by immunohistochemistry $^{14}$ and immunoblotting $^{5}$ techniques, and quantitative assays such as flow cytometry ${ }^{6}$ and enzyme linked immunosorbent assay (ELISA). ${ }^{7}$ Differences in results between studies may also be influenced by the nature of the target antigen used to elicit the immune response which have included murine and human intestinal cells and extracts $^{348}$ and human colonic carcinoma cell lines. ${ }^{57}$

The detection of anti-colon antibodies and assessment of their clinical relevance may be assisted by the availability of a method which permits the simultaneous analysis of multiple samples and avoids subjective interpretation of results. ELISAs are widely used in the assay of antibodies and antigens as they offer distinct advantages over other assays, having a high degree of sensitivity, objectivity, and reproducibility. The aim of this study is to assess the value of ELISAs in the investigation of anti-colon antibodies using human colon carcinoma cell lines as target antigen, which provides a plentiful supply of homogeneous colonic epithelial cell antigens free of contamination from other cell types. In addition, the antigenic determinants of the anti-colon antibody response were examined by immunoblot analysis.

\section{Methods}

PREPARATION OF CELL LINES

Three human cell lines were used: Caco-2, HT-29 (undifferentiated parent cell line), and LS-180 (obtained from the European Collection of Animal Cell Cultures, Division of Biologics, PHLS Centre for Applied Microbiology and Research, Salisbury, Wilts, UK). All are colonic in origin and reported to have antigenic determinants to circulating anti-colon antibodies. ${ }^{579}$ Cell lines were grown in $75 \mathrm{~cm}^{2}$ flasks (Falcon, Franklin Lakes, New Jersey, USA) in either Dulbecco's modified Eagle's medium (Caco-2 and HT-29 cells) or minimum essential medium (LS180 cells) both supplemented with $10 \%$ fetal calf serum, $1 \%$ L-glutamine, $1 \%$ non-essential amino acids, penicillin $(100 \mathrm{IU} / \mathrm{ml})$ and streptomycin (100

Abbreviations used in this paper: IBD, inflammatory bowel disease; ELISA, enzyme linked immunosorbent assay; PBS, phosphate buffered saline; SDS-PAGE, sodium dodecyl sulphate-polyacrylamide gel electrophoresis; BSA, bovine serum albumin; NGS, normal goat serum; PBST, PBS/0.05\% Tween 20 . 
$\mu \mathrm{g} / \mathrm{ml})$ in an atmosphere of $10 \% \mathrm{CO}_{2}$ and $90 \%$ air. When maximum growth was attained, between five and seven days, the cells were detached by mechanical scraping and washed three times with phosphate buffered saline, $\mathrm{pH}$ 7.2 (PBS), with centrifugation at $500 \mathrm{rpm}$ at $4^{\circ} \mathrm{C}$ for 10 minutes between each wash. After the final wash the cell pellet was retained for the preparation of either the whole cell ELISA experiments or sodium dodecyl sulphatepolyacrylamide gel electrophoresis (SDSPAGE) and western blot analysis.

ELISA USING FIXED WHOLE CELLS AS ANTIGEN In order to establish which of the three human cell lines is most suitable as target antigen for ELISA, studies were conducted comparing their immunreactivity to sera obtained from IBD patients and healthy controls. The optimum conditions for the assays were determined from preliminary experiments by varying the concentrations of serum and secondary antibody and the incubation time of the samples.

After their growth and harvest as described above, the cells were counted using a haemocytometer and resuspended in PBS to a final concentration of $1 \times 10^{6} / \mathrm{ml}$. Ninety six well microtitre plates (Falcon) were coated with 100 $\mu \mathrm{l} /$ well of cell suspension (containing $1 \times 10^{5}$ cells) which were allowed to settle and spread at room temperature for 30 minutes and the plates centrifuged for five minutes at 1000 $\mathrm{rpm}$. The supernatant was carefully aspirated from the wells and the plates were air dried and stored at $-20^{\circ} \mathrm{C}$ wrapped in aluminium foil.

Before use, the plates were brought to room temperature, the cells fixed with absolute ethanol at $4^{\circ} \mathrm{C}$ for 10 minutes and air dried. Then $200 \mu \mathrm{l} 2 \%$ bovine serum albumin (BSA) and $1 \%$ normal goat serum (NGS) in PBS with $0.05 \%$ Tween 20 (PBST) were added to each well for one hour at $37^{\circ} \mathrm{C}$ to block non-specific binding sites in the wells. After three washes with PBST, $100 \mu \mathrm{l} /$ well of serum samples diluted $1: 150$ in $2 \% \mathrm{BSA} / 1 \% \mathrm{NGS} / \mathrm{PBST}$ were added in triplicate and incubated for one hour at $37^{\circ} \mathrm{C}$. The serum was discarded and the plates washed five times with PBST. Peroxidase conjugated goat anti-human IgG (Sigma-Aldrich Ltd, Poole, Dorset, UK) diluted 1:5000 with 2\% BSA $/ 1 \%$ NGS/PBST was then added, 100 $\mu \mathrm{l} /$ well, and the plates incubated for one hour at $37^{\circ} \mathrm{C}$. After a further five washes, bound peroxidase was detected by the addition of $150 \mu 1 /$ well of enzyme substrate $\left(0.1 \mathrm{mg} / \mathrm{ml} 3,3,5,5^{\prime}-\right.$ tetramethylbenzidine in $25 \mathrm{mM}$ citric acid/50 $\mathrm{mM} \mathrm{Na} \mathrm{HPO}_{4}$ buffer). All plates were allowed to develop colour until the positive control sera elicited an absorbance exceeding 0.4 at $620 \mathrm{~nm}$ after which the reaction was stopped by the addition of $2 \mathrm{M}$ sulphuric acid. The plates were read using a miniplate reader (LP 400 plate reader; Diagnostics Pasteur) at $450 \mathrm{~nm}$.

To standardise the assay and limit interassay variation, equivalent volumes of serum from five patients with ulcerative colitis were pooled as a single positive control sample which was included in all plates. Comparison of results between different cell lines was made by using the absorbance value of the positive control for each plate as reference, standardised as 1.0. The final result for each serum sample tested was calculated by subtracting the mean of the blank wells (without cells but incubated with serum) from the mean of the test wells, and the difference expressed as a ratio of the positive control result for the plate. To avoid interplate variation of results, each serum sample was assayed concurrently against colonocytes from the three cell lines individually present in triplicate wells within each plate.

IDENTIFICATION OF THE ANTIGENIC

DETERMINANTS OF THE ANTI-COLON ANTIBODY

RESPONSE BY SDS-PAGE AND WESTERN BLOT

ANALYSIS

The cell pellets obtained after harvesting were resuspended in PBS and homogenised at maximum power in a cell homogeniser (Microson), on and off for three minutes in an ice bath, then centrifuged at $3000 \mathrm{rpm}$ for $30 \mathrm{~min}$ utes at $4^{\circ} \mathrm{C}$ to remove unbroken cells and larger cellular fragments. The protein concentration of the clear supernatant for each of the cell homogenates was measured using a bicinchoninic acid assay (BCA protein assay; Pierce, Rockford, Illinois, USA) and stored at $-20^{\circ} \mathrm{C}$ till assayed.

The protein profiles of the cell homogenates were determined by SDS-PAGE using a large gel electrophoresis system to maximise resolution of protein bands. First 22, 25, and $30 \mu \mathrm{g}$ of cell homogenate were solubilized 1:1 in sample buffer $(2 \%$ SDS, $5 \%$ sucrose, $5 \%$ 2-mercaptoethanol, $50 \mathrm{mM}$ Tris/ $\mathrm{HCl}, \mathrm{pH}$ 6.8) and denatured in boiling water for three minutes. The proteins were separated in 5\% stacking- $10 \%$ separating polyacrylamide gels by the method of Laemmli ${ }^{10}$ with molecular mass markers run in separate lanes. After electrophoresis, the gel was stained with Coomassie blue for one hour, then destained in $30 \%$ methanol $/ 7.5 \%$ acetic acid.

Antigenic determinants of the anti-colon antibody response were investigated by western blot analysis. Electrophoresed proteins were transferred to nitrocellulose membranes ${ }^{11}$ and strips of the membrane with transferred cellular protein blocked with $5 \%$ skimmed milk in PBST (milk/PBST) for one hour at $37^{\circ} \mathrm{C}$. The strips were then incubated with test serum diluted 1:50 in milk/PBST overnight at $4^{\circ} \mathrm{C}$, washed three times with $\mathrm{PBS} / 0.5 \%$ Triton $\mathrm{X}-100$, then incubated again for one hour at $37^{\circ} \mathrm{C}$ with peroxidase conjugated goat antihuman IgG diluted 1:1000 in milk/PBST. After three further washes with $\mathrm{PBS} / 0.5 \%$ Triton $\mathrm{X}-100$, the presence of bound immunoglobulin was detected by the addition of substrate solution (3,3'-diaminobenzidine, 4-chloro-1naphthol in sodium phosphate/citric acid buffer) for 10 minutes.

PREVALENCE OF CIRCULATING ANTI-COLON ANTIBODIES IN PATIENTS WITH IBD

Subjects studied

Serum samples obtained from patients with ulcerative colitis, Crohn's disease, or other 
Table 1 Comparative anti-colon antibody ELISAs using whole cell as antigenic substrate

\begin{tabular}{lllll}
\hline & \multicolumn{3}{l}{ Whole cell (mean absorbance) } & Median coefficient of \\
\cline { 2 - 4 } & Caco-2 & HT-29 & LS-180 & variance (\%) \\
\hline Ulcerative colitis & 0.92 & 0.95 & 0.94 & 5.7 \\
Crohn's disease & 0.76 & 0.84 & 0.8 & 6.8 \\
Healthy controls & 0.77 & 0.79 & 0.79 & 4.4
\end{tabular}

Absorbance values are expressed as a ratio of the positive control sera included in all microtitre plates for both studies.

The coefficient of variance between the cell lines was calculated for the serum samples tested from each group.

gastrointestinal disorders and healthy controls were coded and stored at $-70^{\circ} \mathrm{C}$ until assayed.

We studied 55 patients with ulcerative colitis with a median age of 46 years (range 17-73) and median duration of disease of 10 years (range 1-47). The documented extent of disease was substantial involvement of the

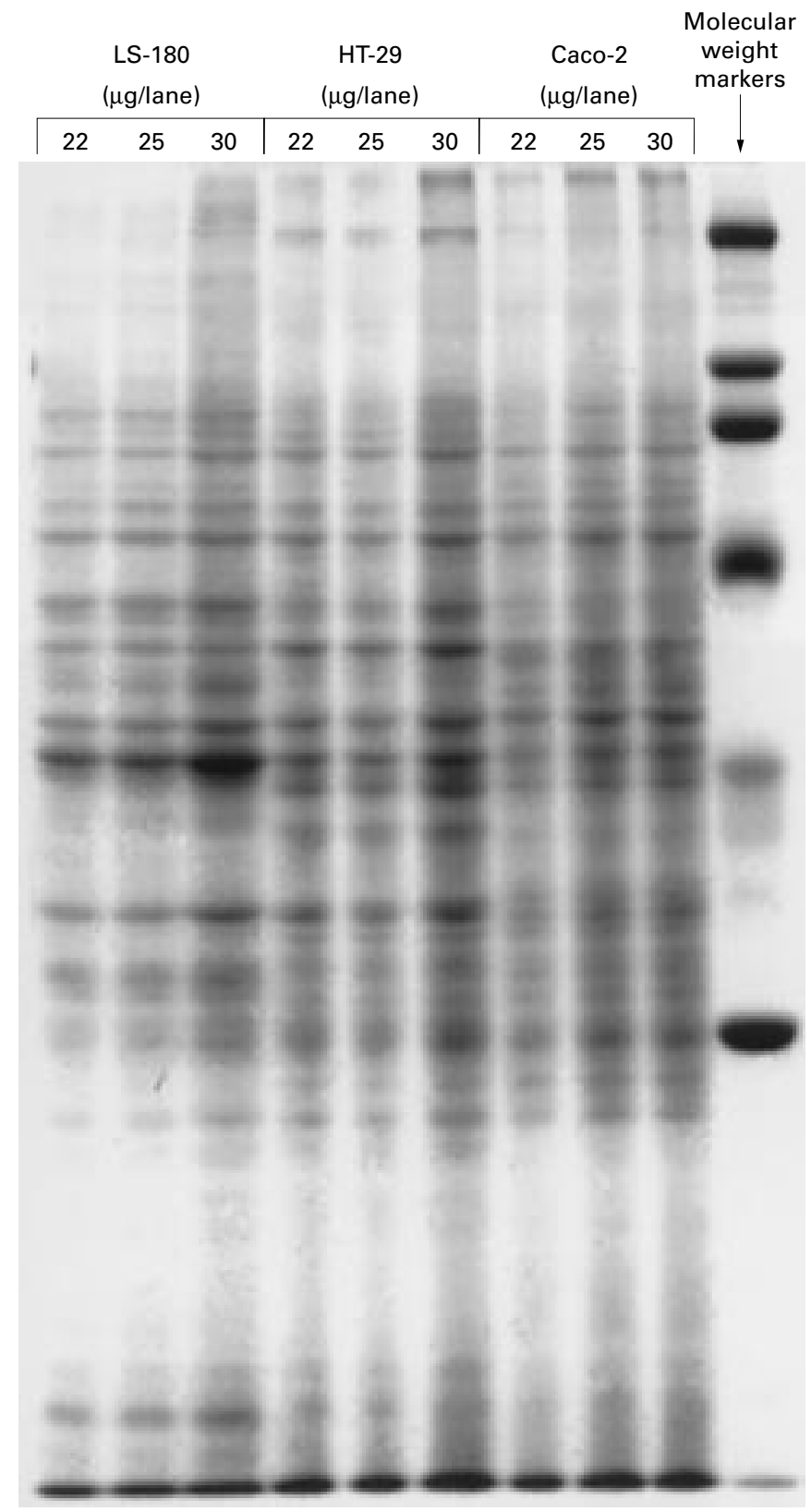

Figure 1 Protein profile of LS-180, HT-29 and Caco-2 cell homogenates separated by 5\% stacking-10\% separating polyacrylamide gels and stained with Coomassie blue. Bands corresponding to similar molecular masses are seen for each of the cells. colon (disease extending proximal to the splenic flexure) in 39, left-sided colitis (rectum, sigmoid, and descending colon) in 10, and distal colitis (rectum with or without sigmoid colon) in six patients. Thirty patients had active disease, defined as a score of 4 or more as assessed by the Sutherland index. ${ }^{12}$ At the time of blood sampling five patients were treated with systemic corticosteroids only, 10 with sulphasalazine or mesalazine alone, 23 with combined therapy, and 17 were on no specific treatment.

For the 94 patients with Crohn's disease, their median age was 35 years (range 15-70) and median disease duration was 10 years (range 1-50). The distribution of disease was colorectal or ileocolic $\left(\mathrm{CD}_{\mathrm{c}}\right)$ in 44 patients whereas only the small bowel was involved in 50 patients $\left(\mathrm{CD}_{\mathrm{SB}}\right)$. Active disease as determined by the Harvey-Bradshaw index ${ }^{13}$ with a score of 5 or more was present in 23 of the colorectal/ileocolic and 25 of the small bowel group. Twelve patients were on corticosteroids only, 14 were treated with sulphasalazine or mesalazine alone, 10 with azathioprine, 24 were on combined therapy and the remainder were on no treatment for their Crohn's disease.

Of the 23 patients investigated with gastrointestinal disorders other than IBD, there were five with colorectal carcinoma, one polyposis coli, four diverticular disease, eight irritable bowel syndrome, three radiation enteritis, and two with microscopic colitis. Their median age was 55 years (range 24-74). Twenty eight healthy controls were studied with a median age of 35.5 years (range 23-55).

\section{Whole cell ELISA}

To investigate the prevalence of anti-colon antibodies amongst IBD patients, whole Caco- 2 cells were used as antigenic substrate in an ELISA. This cell line was selected, as the whole cell ELISA experiments had shown that there were no significant differences in results between the cell lines, but attempts to grow the three types of colonocyte in wells of microtitre plates were only partially successful. Whereas Caco-2 cells achieved $100 \%$ confluence, HT-29 and LS-180 cells did not form satisfactory homogeneous monolayers, their confluency at maturity varying from about 55 to $75 \%$.

Microtitre plates (Falcon) were prepared by seeding individual wells with cells, and growth was maintained with the same medium as described above. After 100\% confluence was attained, between four and six days, the medium was discarded and the cells washed three times with PBS. The plates were then air dried, wrapped in aluminium foil, and stored at $-20^{\circ} \mathrm{C}$. Henceforth the protocol was the same as that outlined in the aforementioned whole cell ELISA experiments.

STATISTICAL ANALYSIS

The immunoreactivity variance between subject groups was analysed by the Kruskal-Wallis test and, when significant, the difference between specific groups was examined by the Mann-Whitney $U$ test. Comparison of the 


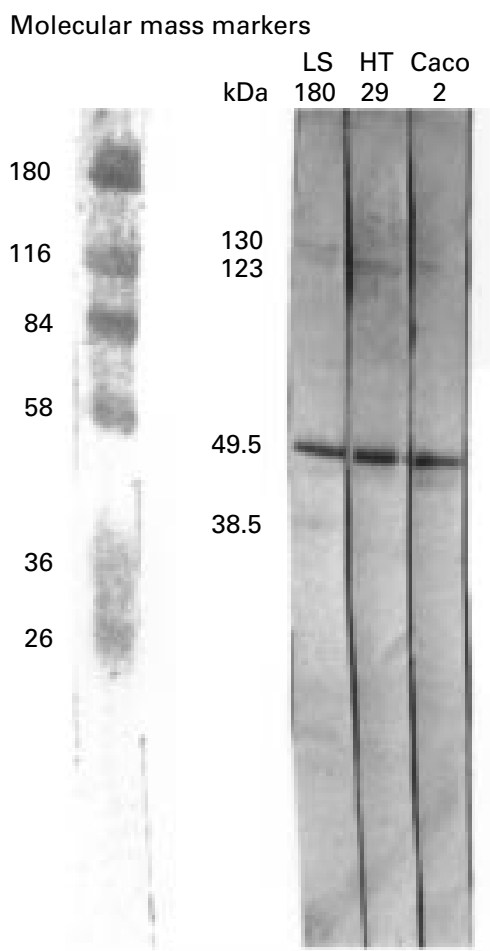

A

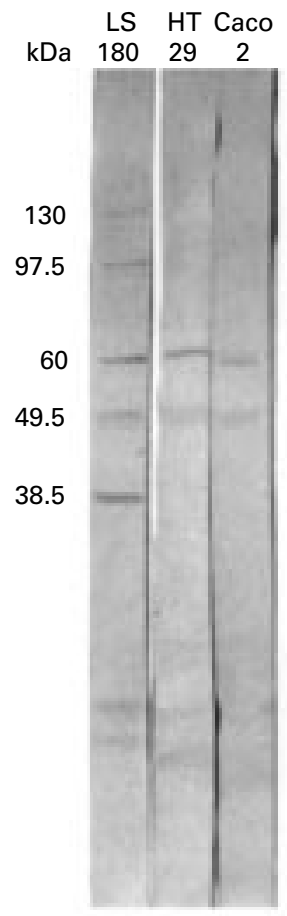

B

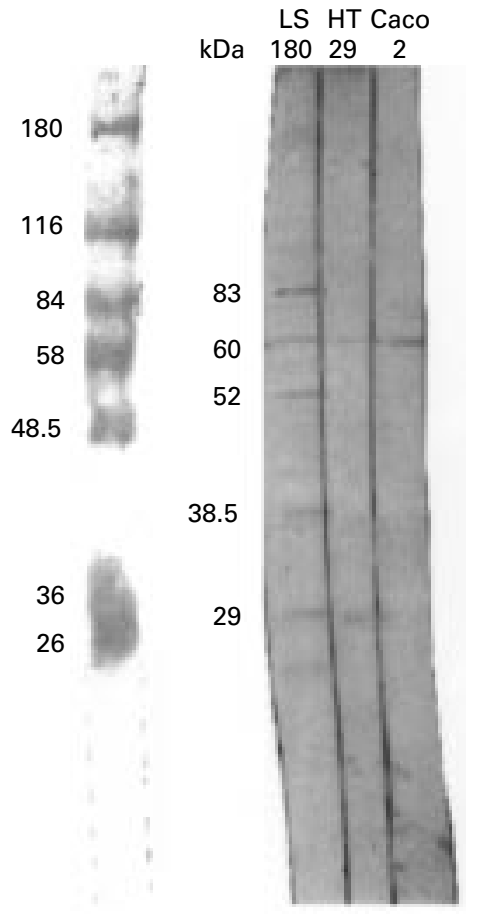

$\mathrm{C}$

Figure 2 Examples of western blot analysis for sera from three patients with ulcerative colitis, (A) (B) and (C). Although the protein profiles of the cell lines are similar (see fig 1) and the nitrocellulose strips were incubated with the same serum sample, circulating antibodies did not recognise protein bands associated with all cells.

prevalence of circulating antibodies between each group was assessed by the $\chi^{2}$ test or Fisher's exact test where appropriate.

\section{Results}

ELISA FOR CIRCULATING ANTIBODIES AGAINST DIFFERENT HUMAN COLONIC CELL LINES

Sera randomly selected from 21 patients with ulcerative colitis, 26 with Crohn's disease, and nine healthy controls were used for this part of the study. Immunoreactivity to the cell lines was similar for each of the groups with sera from patients with ulcerative colitis showing higher absorbance values than patients with Crohn's disease and healthy controls. In addition, there was consistency in the immune response of individual serum samples against each of the cell lines (table 1). The median coefficient of variation for the absorbance values obtained between cell lines for all samples tested was $5.7 \%$ (range $0.3-31 \%$ ).

PROTEIN PROFILES OF COLONOCYTES AND ANTIGENIC DETERMINANTS OF THE ANTI-COLON ANTIBODY RESPONSE

The protein profiles of the different cell homogenates after SDS-PAGE were similar, although differences were observed in the intensity of the bands corresponding to some proteins of the same molecular mass (fig 1). A few bands associated with each of the cells were detected that were absent from one or both of the others, although the intensity of these bands was weak.

Eighteen sera were selected for western blot analysis to investigate the molecular mass of the cellular proteins that correspond to their immunoreactivity. The amount of cell homogenate protein loaded on each gel lane was $30 \mu \mathrm{g}$, as this amount provided the clearest protein profile result on SDS-PAGE. Homogenates from the cell lines were run in parallel lanes of the gel, and, after electrophoretic transfer, the nitrocellulose strips were incubated together with the serum sample to be tested.

Multiple bands corresponding to proteins with different molecular masses were detected (fig 2). Although the protein profile of the three cell lines on SDS-PAGE were similar, immunoreactivity differences to sera were observed. Bands detected on the nitrocellulose strip of one cell line were not necessarily identified on those of the others despite incubation with the same serum sample. Furthermore when bands corresponding to the same molecular mass were visible on the nitrocellulose strip of all cells they showed variable intensity (fig 2).

\section{PREVALENCE OF ANTI-COLON ANTIBODIES AND} CACO-2 CELL ANTIGENIC DETERMINANTS IN PATIENTS WITH IBD

Whole cell ELISA

Immunoreactivity to Caco-2 cells was significantly higher for patients with ulcerative colitis compared with the other groups studied $(\mathrm{p}<0.01)$. The median (range) absorbance was $1.06(0.32-2.61)$ for ulcerative colitis, 0.81 (0-1.71) for Crohn's disease, 0.79 (0.53-1.63) for patients with other gastrointestinal disorders, and $0.66(0.48-1.04)$ for healthy controls. The absorbance values for patients with ulcerative colitis with active disease was $1.11(0.49-1.86)$ which was not significantly different from the 


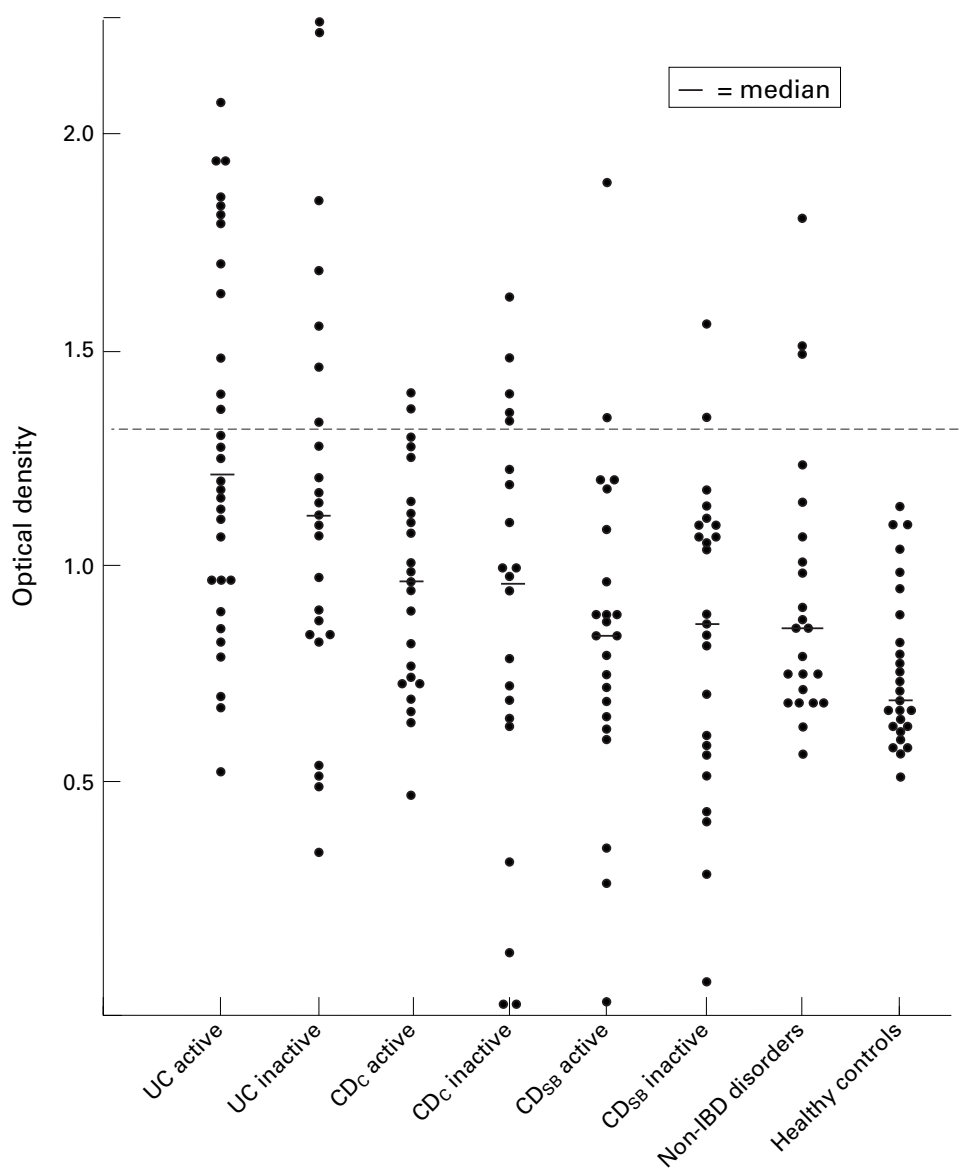

Figure 3 Scattergram of absorbance values obtained by ELISA using fixed whole Caco-2 cells as antigen to investigate the prevalence of anti-colon antibodies in patients with inflammatory bowel disease (IBD). Values above the dotted line are considered positive for anti-colon antibodies, representing results greater than three standard deviations above the mean of the healthy control group. CD, Crohn's disease; UC, ulcerative colitis.

Table 2 Western blot analysis of anti-colon antibody antigenic determinants using Caco-2 cell homogenate as antigen

\begin{tabular}{|c|c|c|c|c|c|}
\hline $\begin{array}{l}\text { Caco-2 cell } \\
\text { protein }(k D a)\end{array}$ & $\begin{array}{l}\text { Ulcerative colitis } \\
(n=34)\end{array}$ & $\begin{array}{l}\text { Crohn's } \\
\text { disease } \\
\text { (colon) } \\
(n=34)\end{array}$ & $\begin{array}{l}\text { Crohn's disease } \\
\text { (small bowel) } \\
(n=35)\end{array}$ & $\begin{array}{l}\text { Other bowel } \\
\text { diseases } \\
(n=10)\end{array}$ & $\begin{array}{l}\text { Healthy } \\
\text { controls } \\
(n=18)\end{array}$ \\
\hline 40.5 & $5(15)$ & $7(21)$ & $9(26)$ & 0 & $2(11)$ \\
\hline 52 & $2(6)$ & $10(29)$ & $5(14)$ & $1(10)$ & $1(6)$ \\
\hline 60 & $3(9)$ & $20(59)$ & $24(69)$ & 0 & $1(6)$ \\
\hline 71 & $4(12)$ & $10(29)$ & $4(11)$ & $1(10)$ & $1(6)$ \\
\hline 77 & 0 & $8(24)$ & 0 & 0 & $1(6)$ \\
\hline 83 & $5(15)$ & $10(29)$ & $10(29)$ & 0 & $2(11)$ \\
\hline 90 & $4(12)$ & $13(38)$ & 3 (9) & 0 & $3(17)$ \\
\hline 105 & $7(21)$ & $1(3)$ & $3(9)$ & 0 & 0 \\
\hline 113 & $8(24)$ & $2(6)$ & 0 & 0 & $1(6)$ \\
\hline
\end{tabular}

Values shown are the number that were positive with percentage in parentheses. Only the major protein bands detected by the sera are listed, the many bands bound by less than $20 \%$ of subjects being excluded.
$(4 \%)$ of the healthy controls $(p<0.01)$. The number of patients with Crohn's disease and other gastrointestinal disorders that were positive for anti-colon antibodies was lower, 23 $(24 \%)$ and $5(22 \%)$ respectively, although significantly higher than healthy controls $(p<0.05)$. The specificity of the assay was only marginally improved if the threshold was increased to three standard deviations above the mean of the healthy controls to define a positive response. Using this criterion, anticolon antibodies were present in 20 (36\%) patients with ulcerative colitis, $12(13 \%)$ with Crohn's disease, and three (13\%) with gastrointestinal disorders other than IBD, all of which remained significant compared with the healthy controls $(0) \quad(p<0.05)$ (fig 3$)$. The prevalence of circulating anti-colon antibodies was similar for ulcerative colitis or patients with Crohn's disease treated with corticosteroids compared with those who were not. The diagnosis of the three non-IBD patients that were positive for anti-colon antibodies were diverticular disease, radiation enteritis, and colorectal carcinoma.

\section{Western blot analysis}

To ascertain the molecular mass of Caco-2 cell proteins corresponding to the whole cell ELISA response, western blot studies were carried out using cell homogenate as antigen. Serum samples selected for analysis were those defined as positive or negative for anti-colon antibodies from the whole cell ELISA. A total of 131 samples were tested from 34 patients with ulcerative colitis, 34 with colorectal/ ileocolic Crohn's disease, 35 with small bowel Crohn's disease, 10 with other gastrointestinal disorders, and 18 healthy controls.

In general, a number of protein bands corresponding to a range of molecular masses were detected for sera from all groups studied. Compared with healthy controls, more bands were detected by sera from IBD patients, and several prominent bands occurred more frequently (table 2). A band corresponding to a protein with an approximate molecular mass of $40 \mathrm{kDa}$ was detected in $15 \%$ of patients with ulcerative colitis, $23 \%$ of patients with Crohn's disease, and $11 \%$ of healthy controls.

\section{Discussion}

The reported prevalence of circulating anticolon antibodies in IBD has varied widely, due in part to differences in assay methodology. In this study we have evaluated human colon cell lines as antigen in ELISAs and applied a simple fixed whole cell ELISA to investigate the prevalence of anti-colon antibodies in patients with IBD. Such a method may be useful for studies that require the screening of a large number of samples.

Circulating antibodies have been described against antigen from different sources, not only to human colonic epithelium but also murine intestinal cells and protein. ${ }^{1348}$ In this study three human colon cell lines were selected for assay, all of which have been reported to show immunoreactivity to IBD sera; Caco-2 cells by western blot, ${ }^{5}$ HT-29 cells by ELISA, ${ }^{7}$ and 
LS-180 cells by immunofluorescence. ${ }^{9}$ The results of our investigations by both ELISA and western blot analysis confirm the presence of circulating antibodies in sera from IBD patients to each of these cell lines.

Solid phase immunoassays are best performed with a single specific antigen. For anticolon antibodies the ideal antigen is yet to be determined. A $40 \mathrm{kDa}$ protein has been reported to be the putative antigen for ulcerative colitis, which, on purification and peptide sequencing, is found to be an isoform of the cytoskeletal protein tropomyosin. ${ }^{14-16}$ However, independent studies have failed to confirm that the predominant autoantigen is a $40 \mathrm{kDa}$ protein, and patients with ulcerative colitis have not been shown to have specific immunoreactivity to tropomyosin. ${ }^{17-19}$ Indeed our immunoblot results show that anti-colon antibodies recognise a number of antigens. Furthermore, although the protein profiles of the cell lines were similar on SDS-PAGE, the same serum sample identified protein bands of different molecular mass for some but not all cell homogenates by western blot, indicating that antibodies recognise different epitopes associated with each of the three types of colonocyte. It is possible that epitopes undergo conformational changes during protein denaturation before gel electrophoresis.

In the absence of an unequivocal autoantigen, human colonic cell lines offer a readily available and homogeneous source of antigen that could be used to investigate the anti-colon antibody response. Although any of the cell lines studied seem appropriate as target antigen, Caco- 2 cells have a distinct advantage over HT-29 and LS-180 cells by virtue of their growth pattern in microtitre plates forming a uniform monolayer.

To examine the applicability of the whole Caco- 2 cell based ELISA, the method was used to study the prevalence of circulating anticolon antibodies in patients with IBD. The results indicate that sera from patients with ulcerative colitis have increased immunoreactivity to Caco-2 cells compared with patients affected with Crohn's disease, other gastrointestinal disorders, and healthy controls. This finding is consistent with the concept that autoimmunity is associated with ulcerative colitis more so than Crohn's disease, as suggested by an increased occurrence of autoimmune disorders amongst patients with ulcerative colitis. $^{20}$ Furthermore, the coexistence of autoantibodies other than anticolon antibodies, such as anti-neutrophil antibodies, has been detected in some patients. ${ }^{71}$ The target antigens of these autoantibodies are yet be identified, and the possibility of antibody cross reactivity cannot be excluded. A higher prevalence of anti-colon antibodies in ulcerative colitis compared with Crohn's disease has also been reported in some studies, ${ }^{215}$ although others have found the frequency of antibodies in the two disorders to be similar. ${ }^{147}$

In our study the anti-colon antibody response was not specific. Antibodies were also present in serum of patients with Crohn's disease and other gastrointestinal disorders, al- though to a lesser degree. This finding remained even when the more stringent criterion of three standard deviations above the mean of the healthy control group was applied to define a positive response. The possibility that anti-colon antibodies arise as a consequence of non-specific intestinal mucosal inflammation cannot be excluded, and inclusion of samples from patients with IBD other than ulcerative colitis or Crohn's disease in further studies would help to clarify this. Another explanation is that our method lacks the sensitivity required to detect specific antigens that are present in low concentrations.

As it had been reported that the autoantigen of the anti-colon antibody response in ulcerative colitis is a $40 \mathrm{kDa}$ colonic protein, ${ }^{14} 15$ western blot analysis was performed to ascertain if the increased prevalence of anti-colon antibodies observed amongst our patients with ulcerative colitis was associated with such a protein. A protein band corresponding to an approximate molecular mass of $40 \mathrm{kDa}$ was detected in only $15 \%$ of patients with ulcerative colitis and in $23 \%$ of patients with Crohn's disease. Caco-2 cell protein bands of other molecular mass were detected by sera from IBD patients but not healthy controls. Further studies are required to ascertain if these proteins are relevant in the immunopathogenesis of IBD.

The significance of circulating anti-colon antibodies in IBD remains obscure. Their presence, regardless of disease activity and the paucity of evidence that they cause epithelial cell damage, ${ }^{4}$ implies that they represent an epiphenomenon of disease. However, antibodies have also been reported amongst healthy relatives of IBD patients, using murine proteins as target antigen, suggesting that they represent disease markers indicative of an underlying genetically determined disturbance of the immune system. ${ }^{32}$ It may be interesting to persue this observation using human antigens. The results of our study indicate that ELISA using whole colonic cells as target antigen is a simple technically feasible and sensitive method of examining the anti-colon antibody response in IBD.

J C W L was supported by the Crohn's in Childhood Research Association, and A M C was a recipient of a grant from the Joint Research Board of St Bartholomew's Hospital.

1 Chapman RW, Cottone M, Selby WS, et al. Serum autoantibodies, ulcerative colitis and primary sclerosing cholangitis. Gut 1986;27:86-91.

2 Hibi T, Ohara $M$, Toda $K$, et al. In vitro anticolon antibody production by mucosal or peripheral blood lymphocytes from patients with ulcerative colitis. Gut 1990;31:1371-6. 3 Fiocchi C, Roche JK, Michener WM. High prevalence of antibodies to intestinal epithelial antigens in patients with inflammatory bowel disease and their relatives. Ann Intern Med 1989;110:786-94

4 Snook JA, Lowes JR, Wu KC, et al. Serum and tissue autoantibodies to colonic epithelium in ulcerative colitis. Gut 1991;32:163-6.

5 Dickey WD, Harley JB, Shireman TJ, et al. Autoantibodies from sera of ulcerative colitis and Crohn's disease patients directed against human cultured colon epithelial cells. [Abstract] Gastroenterology 1991;100:A574.

6 Hibi T, Aiso S, Ishikawa M, et al. Circulating antibodies to surface antigens on colon epithelial cells in ulcerative colitis. Clin Exp Immunol 1983;54:164-8.

7 Hibi T, Ohara M, Kobayashi K, et al. Enzyme linked immunosorbent assay (ELISA) and immunoprecipitation studies on anti-goblet cell antibody using a mucin producing cell
line in patients with inflammatory bowel disease. Gut 1994; 35:224-30. 
8 Marcussen $\mathrm{H}$. Fluorescent anti-colonic and E. coli antibodies in ulcerative colitis. Scand 7 Gastroenterol 1978;13:27781.

9 Hassan T, Kanisawa Y, Squillante L, et al. Expression of a unique epitope in limited colon cancer cell lines that reacts with a novel monoclonal antibody, 7E12H12 and ulcerative colitis (UC) serum. [Abstract] Gastroenterology 1993;104 A711

10 Laemmli UK. Cleavage of structural proteins during the assembly of the head of bacteriophage T4. Nature 1970;227:680-5.

11 Towbin H, Staehelin T, Gordon J. Electrophoretic transfer of proteins from polyacrylamide gels to nitrocellulose sheets: procedure and some applications. Proc Natl Acad Sci USA 1979;76:4350-4.

12 Sutherland LR, Martin F, Greer S, et al. 5-Aminosalicylic acid enema in the treatment of distal ulcerative colitis, proctosigmoiditis, and proctitis. Gastroenterology 1987; 92:1894-8.

13 Harvey RF, Bradshaw JM. A simple index of Crohn's disease activity. Lancet 1980;1:514-15.

14 Takahashi F, Das KM. Isolation and characterization of colonic autoantigen specifically recognised by colon tissue bound immunoglobulin $\mathrm{G}$ from idiopathic ulcerative colitis. 7 Clin Invest 1985; 76:311-18.

15 Takahashi F, Shah HS, Wise LS, et al. Circulating antibodies against human colonic extract enriched with a $40 \mathrm{kDa}$ protein in patients with ulcerative colitis. Gut 1990;31: 1016-20.

16 Das KM, Dasgupta A, Mandal A, et al. Autoimmunity to cytoskeletal protein tropomyosin. A clue to the pathogenetic mechanism for ulcerative colitis. F Immunol 1993;150: 2487-93.

17 Cantrell M, Prindiville T, Gershwin ME. Autoantibodies to colonic cells and subcellular fractions in inflammatory bowel disease: do they exist ? F Autoimmun 1990;3:307-20.

18 Hamilton MI, Bradley NJ, Srai SK, et al. Autoimmunity in ulcerative colitis: tropomyosin is not the major antigenic determinant of the Das monoclonal antibody, 7E12H12. Clin Exp Immunol 1995;99:404-11.

19 Khoo UY, Bjarnason I, Donaghy A, et al. Antibodies to colonic epithelial cells from the serum and colonic mucosal washings in ulcerative colitis. Gut 1995;37:63-70.

20 Snook JA, de Silva HJ, Jewell DP. The association of autoimmune disorders with inflammatory bowel disease. $O \not M$ 1989;72:835-40.

21 Seibold F, Weber P, Klein R, et al. Clinical significance of antibodies against neutrophils in patients with inflammatory bowel disease and primary sclerosing cholangitis. Gut 1992;33:657-62.

22 Lagercrantz R, Perlmann P, Hammarstrom S. Immunological studies in ulcerative colitis. V. Family studies. Gastroenterology 1971;60:381-9. 